\title{
Experimental Study on Mechanical Property and Pore Distribution of Limestone Specimens after Heat Treatment under Different Heating Conditions
}

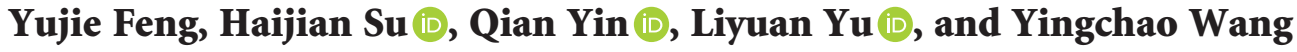 \\ State Key Laboratory for Geomechanics and Deep Underground Engineering, China University of Mining and Technology, \\ Xuzhou, Jiangsu 221116, China \\ Correspondence should be addressed to Haijian Su; hjsu@cumt.edu.cn
}

Received 26 March 2021; Accepted 7 June 2021; Published 18 June 2021

Academic Editor: Fengqiang Gong

Copyright (c) 2021 Yujie Feng et al. This is an open access article distributed under the Creative Commons Attribution License, which permits unrestricted use, distribution, and reproduction in any medium, provided the original work is properly cited.

The thermal effect of rocks not only depends on the temperature level but also may be influenced by the factors including heating environment, heating rate, and cooling method. In this study, approximate vacuum (V) and air circulation (A) heating condition are, respectively, applied on the limestone specimens in the whole heating process. Then, physical, mechanical, and nuclear magnetic resonance (NMR) tests were carried out to investigate the effect of heating conditions on the rock properties. The results show that heating conditions have significant effects on mechanical properties of limestone specimens (including peak strength, elasticity modulus, secant modulus, and crack initiation stress), which are due to the interference effect on the oxidation and thermal decomposition. It is worth noting that the significant temperature range of the heating condition is $450 \sim 750^{\circ} \mathrm{C}$, during which the mechanical performances of heat-treated specimens under $\mathrm{V}$ condition obviously outperform those under A condition. Combining the NMR results and the microstructure images from scanning electron microscope (SEM) technology, the evolution of pore distribution was revealed. As temperature increases from room temperature to $900^{\circ} \mathrm{C}$, porosity increases gradually. However, pore distribution changes from small and medium pores dominating to large pore dominating and then to medium pore dominating. For limestone specimens after high-temperature treatment above $450^{\circ} \mathrm{C}$, mineral crystals may melt and reconsolidate, filling in some of the previously large pores generated by thermal decomposition.

\section{Introduction}

In many countries, such as England, Switzerland, and China, energy application has entered the stage of cleaning, efficiency, and diversification. As a recognized green resource, deep geothermal energy can provide a great amount of heat, and the impact of rock thermal effect on engineering is a problem that cannot be ignored $[1,2]$. Thermal effect would lead to the changes in mineral composition and microstructure of rock and thus affect the mechanical behaviors and the stability of rock mass [3-6]. In underground coal gasification, tunnel fire, the deep storage of high-level nuclear waste, and other rock engineering projects [7-11], the thermal effect on rock has also been observed and become a hot topic. There is a growing demand for knowledge on mechanical properties of thermally treated rock to provide a basis for the performance and safety analysis of those corresponding projects [12-15]. For instance, Kim et al. [16] conducted laboratory tests on three types of rock specimens to explore the effect of rapid thermal cooling on the physical and mechanical properties, and they found that rocks with stronger heterogeneity and coarser grain are more likely to exhibit crack growth. Uniaxial compression strength testing of Hawkesbury sandstone at different temperature was conducted by Ranjith et al. [17], which showed that both the compressive strength and elastic modulus present various changes when the heating temperature is above or below $500^{\circ} \mathrm{C}$. Peng et al. [18] investigated the evolution characteristics of fracture by carrying out semicircular three-point bending tests on granite specimens treated with different high temperature and concluded that the temperaturesensitive ranges of granite are different under different 
fracture modes. In addition, the pore characteristics and distribution of rocks are the main factors affecting the properties of rocks after high temperature $[19,20]$. So Zhang et al. [21] and Yin et al. [22] used the mercury intrusion method to study the pore characteristics of thermally treated sandstone and granite, respectively. The results showed that the cumulative pore volumes of granite and sandstone increase with growing temperature, and pore structure of sandstone changes dramatically between 400 and $600^{\circ} \mathrm{C}$. Nuclear magnetic resonance (NMR) tests were conducted by Zhang et al. [23] and Weng et al. [24] to detect the pore structure characteristics of red sandstone and granite. The results of transverse relaxation time $\left(T_{2}\right)$ and signal amplitude were analyzed to obtain the influence of temperature on rock.

The physical and mechanical properties of limestone, which is a common sedimentary rock, in many rock projects are the important basis for the evaluation of engineering stability. Abd El-Aal and Masoud [25] studied the mechanical and petrophysical properties of the karst limestone to evaluate the impact of karsts phenomena on engineering properties of limestone foundation bed in Ar Riyadh in Saudi Arabia. Infrared radiation was observed and detected by Wang et al. [26] to investigate the entire deformation and failure process of limestone specimens from the roof of a coal seam in Xiezhuang Mine of China under uniaxial compression. Xu et al. [27] displayed a series of large triaxial tests on the limestone rockfill specimens along different loading paths. In recent years, the physical, mechanical, and permeability properties of limestone at high temperature have attracted more and more attention of scholars. Zhang et al. [28] investigated the pore, mechanics, and acoustic emission (AE) features of limestone under the influence of temperature ranging from 25 to $600^{\circ} \mathrm{C}$. Crosby et al. [29] studied the mechanical behaviors of Salem limestone containing thermally induced microcracks.

At present, studies regarding the thermal effect of rocks primarily focused on the temperature level and cooling method of high temperature treatment. In fact, the variations of other heating conditions such as the heating rate, constant temperature duration, and heating environment also have a significant impact on thermal effect [16, 30-32]. For some special rock issues, such as underground gasification of coal, tunnel fire, and gas explosion, the heating process of rock usually occurs in the environment with low concentration of air. Yu et al. [33] conducted split Hopkinson pressure bar (SHPB) tests on limestone specimens heated in quasi-vacuum and air-filled environments, respectively, and found that the heating environment played a remarkable role between 450 and $900^{\circ} \mathrm{C}$. Uniaxial compression tests were conducted by Su et al. [34] on marble specimens to investigate the influence of thermal environment on mechanical behaviors. They concluded that both the peak stress and elastic modulus in vacuum environment were larger than those in airiness environment at the same temperature.

In this study, to investigate the mechanical properties and pore distribution of rock induced by low concentration of air, limestone specimens were selected as experimental object and were heated to six temperature levels of $200 \sim 900^{\circ} \mathrm{C}$ under two different heating conditions, that is, approximate vacuum and air circulation condition, respectively. Then, physical and mechanical tests were conducted on the thermally treated specimens to investigate the influence of heating conditions on rock properties. The pore distribution and microstructure were also observed by means of the NMR and scanning electron microscope (SEM) technologies. AE method was applied during the uniaxial compression tests and the evolution of crack initiation stress with temperature was obtained on the basis of acoustic results.

\section{Materials and Methods}

The limestone was collected from Xuzhou, Jiangsu Province, China. It is dark gray without visible texture in natural state and belongs to the Zhangxia Group of Middle Cambrian Series. As a sedimentary rock, the limestone shows a relative uniformity (see Figure 1). The mineral grain of limestone shows the blocky morphology with a regular and tight arrangement. According to the magnetic resonance imaging (MRI) image, it is mainly characterized by fine pores, without obvious macroscopic crack. The X-ray diffraction (XRD) result (as shown in Figure 2) displays that the mineral composition of tested limestone mainly contains magnesium calcite, calcium carbonate, and sinnerite. The average density is $2.74 \mathrm{~g} / \mathrm{cm}^{3}$ and the ultrasonic velocity is $5.35 \mathrm{~km} / \mathrm{s}$ for original limestone blocks.

Standard cylinder specimens with a diameter of $50 \mathrm{~mm}$ and height of $100 \mathrm{~mm}$ were machined from the limestone block using a diamond drill. The deviation of specimen height was within $0.2 \mathrm{~mm}$, and the nonparallelism between two end surfaces was controlled within an error of $0.05 \mathrm{~mm}$. The prepared limestone specimens were subjected to heat treatment using a MXQ1700 box-type furnace produced by Shanghai Micro-X Furnace Co. Ltd. (China) as shown in Figure 3(a). Two kinds of heating conditions were investigated: approximate vacuum and air circulation. For the approximate vacuum condition (simply $\mathrm{V}$ later), air was driven from the furnace by a vacuum pump before heat treatment to achieve an approximate vacuum environment, with the chamber pressure below atmospheric pressure of $40 \mathrm{kPa}$. Meanwhile, for the air circulation condition (simply A later), both inlet and vent valves were turned on at the same time to allow the air to flow through the furnace continuously and slowly in the whole heating process. The limestone specimens were firstly heated to the designed temperature $\left(200,300,450,600,750\right.$, and $\left.900^{\circ} \mathrm{C}\right)$ at a constant heating rate of $5^{\circ} \mathrm{C}$ per minute. Then, the specimens were held at the designed temperature for 2 hours to ensure uniform heating of the specimens. Finally, limestone specimens were naturally cooled to room temperature in the furnace. The whole heating treatment process was accomplished under the approximate vacuum or air circulation condition. The heating methods and limestone specimens after heat treatment are shown in Figures 3(b) and 3(c).

After heat treatment, the ultrasonic velocity of tested limestone under different heating conditions was measured 


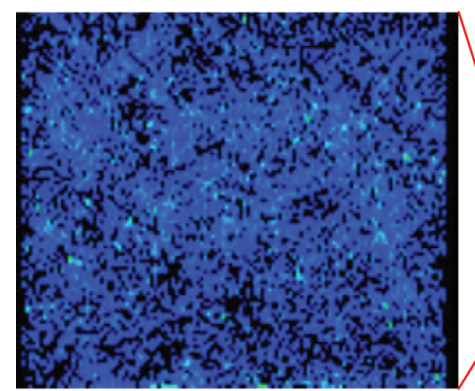

MRI
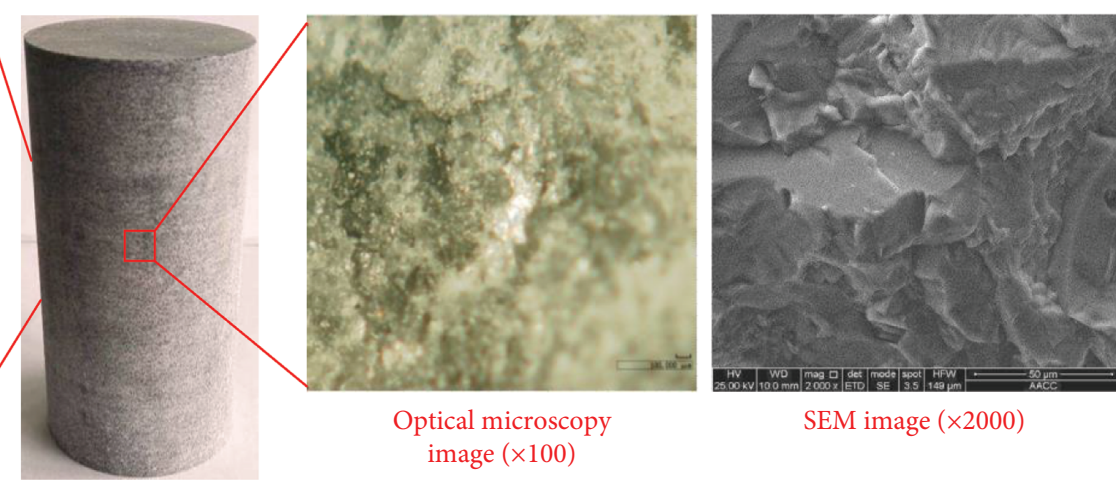

SEM image $(\times 2000)$

Figure 1: Microstructure of limestone.

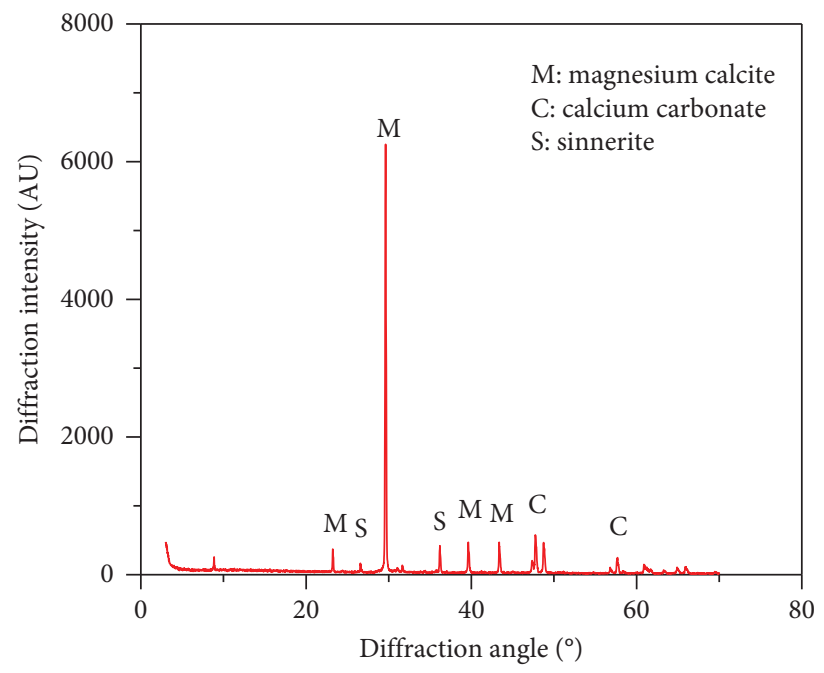

FIGURE 2: XRD result of tested limestone.

by HC-U81 ultrasonic wave tester. Vaseline was applied as the coupling agent between the specimen and the ultrasonic sensor. Besides, NMR tests were conducted on limestone after heat treatment to achieve the microscopic pore features by MesoMR23-060H-I nuclear magnetic resonance spectrometer. The resonance frequency of the device is $23.423 \mathrm{MHz}$ and the probe coil diameter is $60 \mathrm{~mm}$. The limestone specimens were firstly dried in an oven at $105^{\circ} \mathrm{C}$ for 12 hours and then the cooled specimens were saturated in a vacuum-pressurized saturation device for 72 hours. Subsequently, the NMR results of saturated specimens were achieved. The radius of these microscopic pores was calculated based on the NMR data. To further analyze the distribution feature of microscopic pore, an evaluation coefficient $p e\left(r_{1}-r_{2}\right)$ is proposed, as shown in the following equation:

$$
P e\left(r_{1} \sim r_{2}\right)=\frac{N\left(r_{1} \sim r\right)_{2}}{N_{a}} \times 100 \%,
$$

where $N_{a}$ is the total volume of microscopic pore in rock and $N\left(r_{1}-r_{2}\right)$ is the volume of microscopic pore with the radius between $r_{1}$ and $r_{2}$.

At last, the limestone specimens were conducted to uniaxial compression tests using a MTS815 rock mechanics servo-controlled testing system. During the testing process, displacement-controlled condition was used with a constant loading rate of $3.0 \times 10^{-3} \mathrm{~mm}$ per second. Axial stress and strain were collected automatically by the computer. During the loading process, acoustic signals were also detected by a PCIE-Q87-i2 rock acoustic tester produced by Physical Acoustics Corporation (America).

\section{Results Analysis and Discussion}

3.1. Physical Properties. The variations in density $(p)$ and ultrasonic velocity $(v)$ of limestone with different temperatures under $\mathrm{V}$ and $\mathrm{A}$ conditions are, respectively, shown in Figure 4 and the specific data are displayed in Table 1. With the increase of temperature, both the density and ultrasonic velocity present a decreasing trend. As temperature rises from 200 to $900^{\circ} \mathrm{C}$, the density decreases by $6.20 \%$ for $\mathrm{V}$ condition and by $6.67 \%$ for A condition. Similarly, the ultrasonic velocity decreases by $59.84 \%$ for $\mathrm{V}$ condition and by $62.61 \%$ for A condition. Moreover, the interesting thing is that the decline rate of the density and ultrasonic velocity are not synchronized when the temperature is higher or lower than $600^{\circ} \mathrm{C}$. Taking A condition as an example, the density decreases slowly first at $200 \sim 600^{\circ} \mathrm{C}$, with the reduction 


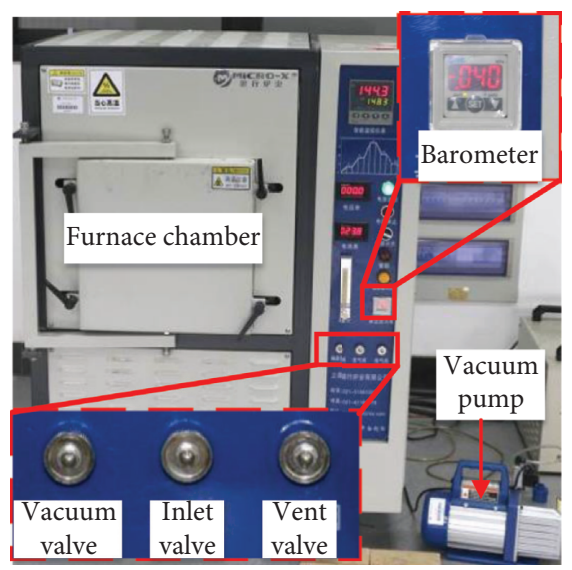

(a)

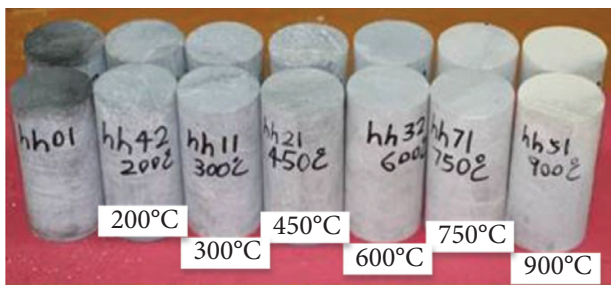

(b)

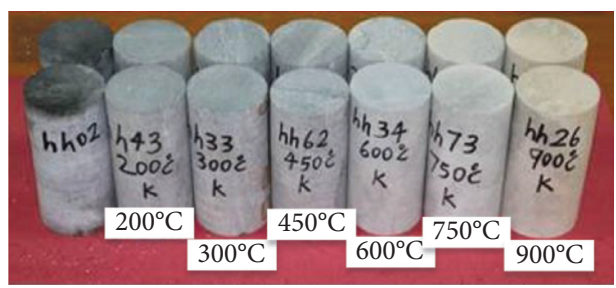

(c)

Figure 3: (a) MXQ1700 box-type furnace, and the heating methods and limestone specimens after heat treatment under (b) V and (c) A conditions, respectively.

extent of $1.43 \%$. Then, a drastic drop of density presents from 600 to $900^{\circ} \mathrm{C}$, with the reduction extent of $5.25 \%$. However, the ultrasonic velocity of limestone specimen declines sharply by $51.54 \%$ at $200 \sim 600^{\circ} \mathrm{C}$ and decreases slightly by $22.91 \%$ between 600 and $900^{\circ} \mathrm{C}$. It is mainly due to the evaporation of different types of water (pore water, combined water, crystal water, and zeolite water) into steam from 100 to $500^{\circ} \mathrm{C}$, leading to the generation of several forms of microscopic cracks [35]. The occurrence of microcracks has little influence on the density but leads to a serious reduction on the ultrasonic velocity. When the temperature is above $500^{\circ} \mathrm{C}$, the magnesium calcite $\left(\mathrm{MgCO}_{3}\right)$ starts to be decomposed into $\mathrm{MgO}$ and $\mathrm{CO}_{2}$ at around $520^{\circ} \mathrm{C}$. The thermal decomposition of calcium carbonate $\left(\mathrm{CaCO}_{3}\right)$ also starts at around $530^{\circ} \mathrm{C}$ and becomes dramatic around $897^{\circ} \mathrm{C}$ $[28,36]$. Therefore, the density shows a dramatic reduction, while the ultrasonic velocity shows a relatively small variation after the drastic degradation in the previous stage.

It can also be seen from Figure 4 that the variations of density and ultrasonic velocity of limestone are not only related to the change of temperature but also related to the heating conditions. The variations of density under two conditions remain synchronized in general and the difference between them is not significant. However, the values in $\mathrm{V}$ condition are generally larger than those in A condition in terms of ultrasonic velocity. Therefore, it can be inferred from the characteristics shown in ultrasonic velocity that the continuous air could promote the thermal action and the heating condition plays a considerable role in the thermal treatment of limestone.

3.2. Mechanical Properties. In the tunnel fire and gas explosion accidents, the rocks near the lining are subjected to high temperature treatment with air circulation, while the inner rocks reach a high temperature in an approximate vacuum environment. The difference in the mechanical properties of rocks under such two different heating conditions would increase the difficulty of design and influence the stability of engineering. The variations in mechanical parameters of limestone specimens versus the treated temperature under uniaxial compression are shown in Figure 5, including peak strength, peak strain (indicating the corresponding axial strain of peak strength), elasticity modulus, and secant modulus. The detailed results are 


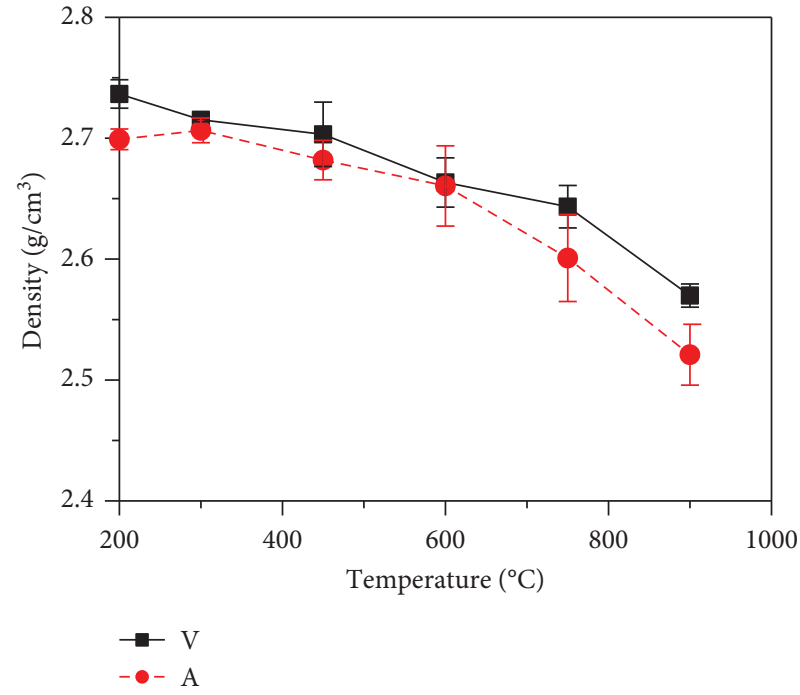

(a)

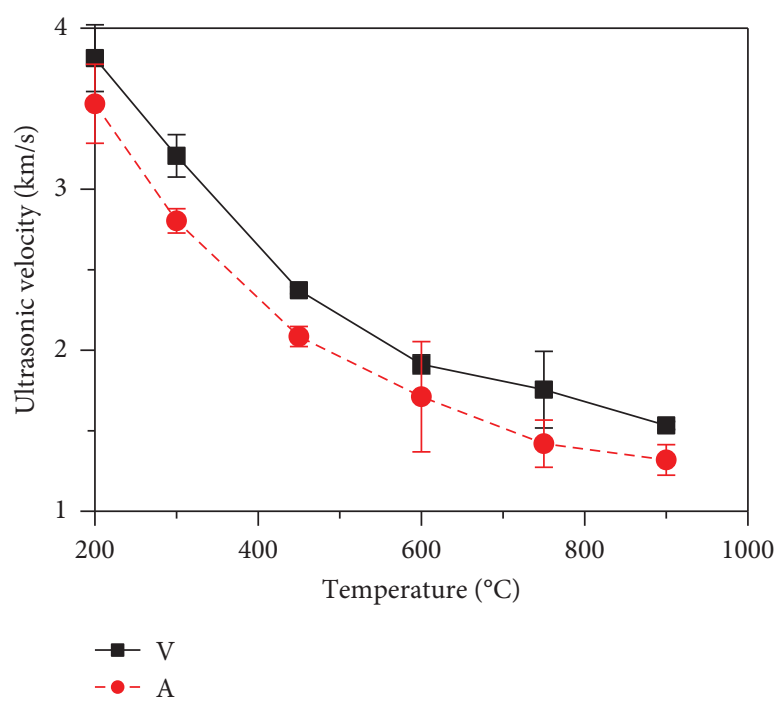

(b)

Figure 4: Variations in (a) density and (b) ultrasonic velocity of limestone with different temperatures under different heating conditions (error bar indicates one standard deviation).

Table 1: Physical and mechanical parameters of limestone after heat treatment under different heating conditions.

\begin{tabular}{|c|c|c|c|c|c|c|c|c|c|c|c|c|c|c|c|c|}
\hline \multirow{2}{*}{$T\left({ }^{\circ} \mathrm{C}\right)$} & \multicolumn{2}{|c|}{$\rho\left(\mathrm{g} / \mathrm{cm}^{3}\right)$} & \multicolumn{2}{|c|}{$v(\mathrm{~km} / \mathrm{s})$} & \multicolumn{2}{|c|}{ UCS (MPa) } & \multicolumn{2}{|c|}{$\varepsilon_{0}\left(\times 10^{-2}\right)$} & \multicolumn{2}{|c|}{$E_{\mathrm{a}}(\mathrm{GPa})$} & \multicolumn{2}{|c|}{$E_{50}(\mathrm{GPa})$} & \multicolumn{2}{|c|}{$\sigma_{\mathrm{ci}}(\mathrm{MPa})$} & \multicolumn{2}{|c|}{$\sigma_{\mathrm{ci}} / \mathrm{UCS}$} \\
\hline & $\mathrm{Me}$ & St & $\mathrm{Me}$ & St & $\mathrm{Me}$ & St & $\mathrm{Me}$ & St & $\mathrm{Me}$ & St & $\mathrm{Me}$ & St & $\mathrm{Me}$ & St & $\mathrm{Me}$ & St \\
\hline 25 & 2.74 & 0.021 & 5.35 & 0.238 & 121.60 & 3.393 & 0.53 & 0.001 & 28.84 & 1.538 & 20.92 & 0.902 & 55.38 & 1.175 & 0.46 & 0.016 \\
\hline $200-\mathrm{V}$ & 2.74 & 0.012 & 3.81 & 0.207 & 105.72 & 1.160 & 0.59 & 0.047 & 25.22 & 0.827 & 16.17 & 1.605 & 50.22 & 1.810 & 0.47 & 0.012 \\
\hline $200-A$ & 2.70 & 0.009 & 3.53 & 0.245 & 92.66 & 3.635 & 0.58 & 0.059 & 24.45 & 1.450 & 14.46 & 1.485 & 40.63 & 2.758 & 0.44 & 0.013 \\
\hline $300-\mathrm{V}$ & 2.72 & 0.002 & 3.21 & 0.132 & 91.27 & 2.114 & 0.61 & 0.013 & 21.58 & 0.629 & 12.71 & 0.764 & 40.47 & 2.630 & 0.44 & 0.019 \\
\hline $300-A$ & 2.71 & 0.010 & 2.80 & 0.076 & 78.46 & 4.879 & 0.64 & 0.003 & 19.50 & 0.905 & 9.97 & 1.025 & 33.97 & 3.939 & 0.43 & 0.023 \\
\hline $450-\mathrm{V}$ & 2.70 & 0.027 & 2.37 & 0.021 & 88.98 & 8.309 & 0.86 & 0.028 & 17.04 & 0.976 & 8.47 & 0.643 & 36.54 & 2.836 & 0.41 & 0.007 \\
\hline $450-\mathrm{A}$ & 2.68 & 0.016 & 2.09 & 0.062 & 74.43 & 2.539 & 0.87 & 0.041 & 13.09 & 0.665 & 7.11 & 0.262 & 28.83 & 3.260 & 0.39 & 0.057 \\
\hline $600-\mathrm{V}$ & 2.66 & 0.020 & 1.91 & 0.059 & 76.76 & 3.288 & 1.00 & 0.012 & 12.87 & 1.506 & 6.49 & 0.113 & 30.01 & 2.135 & 0.39 & 0.045 \\
\hline $600-A$ & 2.66 & 0.033 & 1.71 & 0.342 & 63.18 & 0.354 & 1.05 & 0.043 & 9.79 & 1.117 & 4.77 & 0.276 & 21.79 & 1.146 & 0.34 & 0.016 \\
\hline $750-\mathrm{V}$ & 2.64 & 0.018 & 1.76 & 0.238 & 65.66 & 5.480 & 1.23 & 0.045 & 8.68 & 0.071 & 4.15 & 0.255 & 24.12 & 2.291 & 0.37 & 0.004 \\
\hline 750-A & 2.60 & 0.036 & 1.42 & 0.146 & 53.89 & 1.499 & 1.28 & 0.082 & 7.06 & 0.495 & 3.29 & 0.212 & 17.32 & 1.704 & 0.32 & 0.041 \\
\hline $900-\mathrm{V}$ & 2.57 & 0.010 & 1.53 & 0.025 & 35.89 & 2.242 & 1.33 & 0.033 & 4.39 & 0.905 & 2.17 & 0.007 & 11.78 & 1.414 & 0.33 & 0.060 \\
\hline $900-\mathrm{A}$ & 2.52 & 0.025 & 1.32 & 0.095 & 30.81 & 1.796 & 1.49 & 0.028 & 2.50 & 0.007 & 2.05 & 0.134 & 9.71 & 0.552 & 0.32 & 0.000 \\
\hline
\end{tabular}

Note: Me and St indicate the mean value and standard deviation, respectively; " $200-\mathrm{V}^{\prime}$ means $200^{\circ} \mathrm{C}$ under vacuum condition, and the others are the same.

displayed in Table 1, in which UCS indicates the uniaxial compressive strength, $\varepsilon_{0}$ indicates the peak strain, $E_{a}$ indicates the elasticity modulus, and $E_{50}$ indicates the secant modulus, respectively. With the increase of temperature, the peak strength, elasticity modulus, and secant modulus all present a decreasing trend in general, while the peak strain increases gradually. It can be observed that the peak strength does not decrease dramatically below $450^{\circ} \mathrm{C}$ but drops sharply when the temperature is above $450^{\circ} \mathrm{C}$, especially when temperature reaches $900^{\circ} \mathrm{C}$. The possible reason for this phenomenon may be that the thermal decomposition of magnesium calcite and calcium carbonate occurs until the temperature is above $500^{\circ} \mathrm{C}$ and calcium carbonate decomposes dramatically around $900^{\circ} \mathrm{C}[28,36]$. The occurrence of thermal decomposition aggravates the generation and propagation of lots of microcracks, which further leads to the deterioration of peak strength.
The heating condition not only affects the physical behaviors but also influences the mechanical parameters. The peak strength, elasticity modulus, and secant modulus for A condition are lower than those for $\mathrm{V}$ condition in general, while the peak strain presents the opposite feature. Taking $T=600^{\circ} \mathrm{C}$ as an example, the peak strength, elasticity modulus, and secant modulus of $\mathrm{V}$ condition are relatively $17.69 \%, 23.93 \%$, and $26.50 \%$ higher than those under $\mathrm{A}$ condition, respectively. Therefore, it can be inferred that the limestone under A condition experiences more thermal damage compared to $\mathrm{V}$ condition, which may be related to the thermal decomposition of minerals under the circulation of air.

In order to quantitatively describe the effect of heating environment on the mechanical parameters of limestone specimens, the variations in $M_{A} / M_{V}$ were calculated, as shown in Figure 6, in which MA and $M V$ are defined as the 

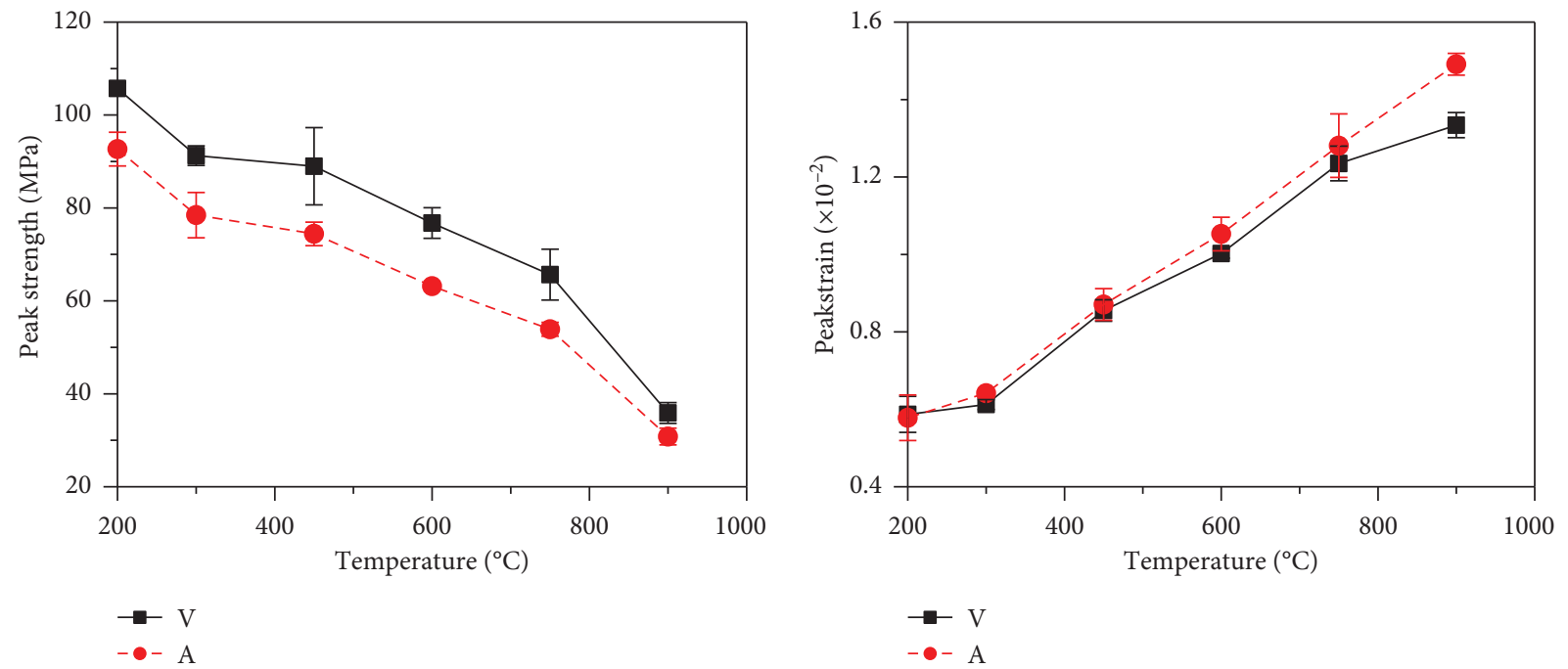

(a)

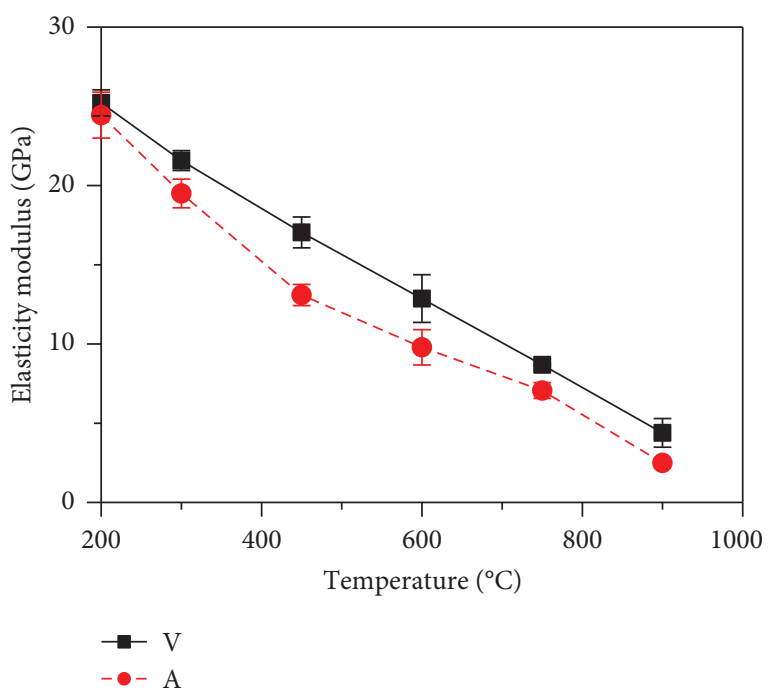

(c)

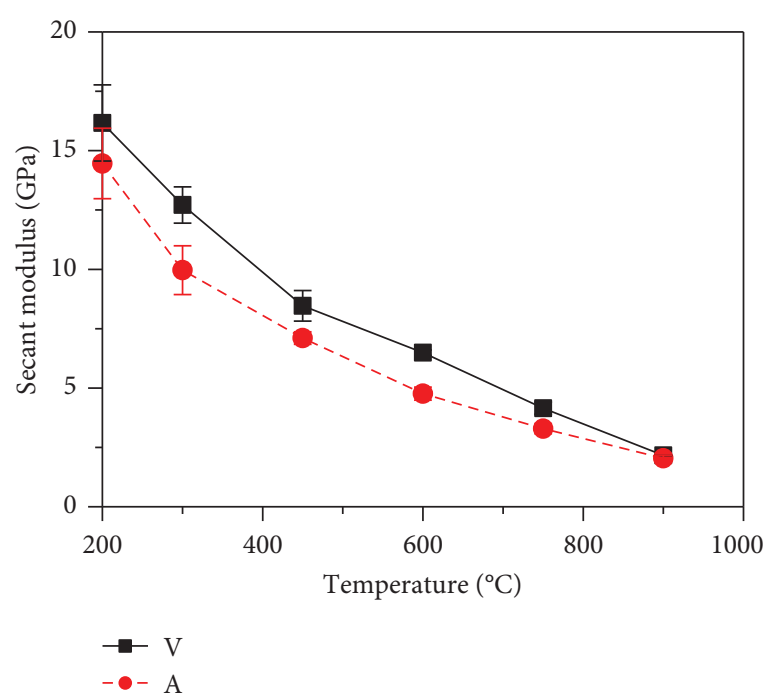

(d)

FIGURE 5: Variations in (a) peak strength, (b) peak strain, (c) elasticity modulus, and (d) secant modulus versus the treated temperature (error bar indicates one standard deviation).

mechanical parameters of specimens after heat treatment under $\mathrm{A}$ and $V$ conditions, respectively. The smaller $M_{A} / M_{V}$ is, the more remarkable the influence of heating condition on the mechanical property of rock after heat treatment is. From Figure 6, a temperature range of significant influence of $450 \sim 750^{\circ} \mathrm{C}$ is revealed, which may be related to the thermal decomposition of limestone. Under $\mathrm{V}$ condition, the decomposed $\mathrm{CO}_{2}$ from magnesium calcite $\left(\mathrm{MgCO}_{3}\right)$ and calcium carbonate $\left(\mathrm{CaCO}_{3}\right)$ cannot be discharged and stick around the mineral grains, inhibiting the thermal reaction to some extent. No matter $\mathrm{V}$ condition or A condition, high temperature has severely deteriorated the mechanical properties of limestone specimens, and dramatic thermal decomposition has occurred in the rocks at $900^{\circ} \mathrm{C}$. The values of peak strength, elasticity modulus, and secant modulus all drop into a relatively low level at $900^{\circ} \mathrm{C}$. So $M_{\mathrm{A}} /$ $M_{\mathrm{V}}$ of peak strength and secant modulus increased slightly from $750^{\circ} \mathrm{C}$ to $900^{\circ} \mathrm{C}$. However, $M_{\mathrm{A}} / M_{\mathrm{V}}$ of elasticity modulus experienced a significant decrease within this temperature range, which may result from the fact that these two conditions have similar peak strength and A condition has a larger peak strain. It can be inferred that limestone specimens under $\mathrm{A}$ condition at $900^{\circ} \mathrm{C}$ present a more obvious ductility.

Figure 7 shows the optical microscopy images of limestone after heat treatment. Between 200 and $450^{\circ} \mathrm{C}$, the thermal effect of limestone mainly manifests as the thermal cracking due to the nonuniform thermal expansion among the mineral grains $[37,38]$. The bonding properties among grains were weakened gradually. Above $450^{\circ} \mathrm{C}$, some mineral grains and crystals were melted and reconsolidated. Limestone presents the significant thermal decomposition, resulting in the performance deterioration of mineral grains [39]. Especially at $900^{\circ} \mathrm{C}$, calcium carbonate decomposes 


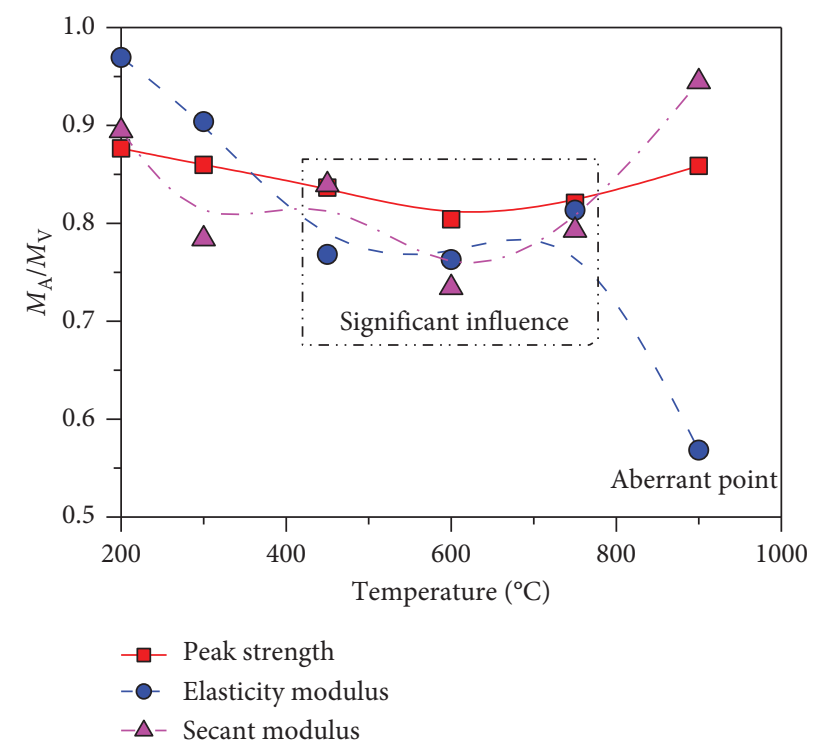

Figure 6: Variation in $(M)_{A} /(M)_{V}$ with different temperatures.

dramatically and large cracks appear between the mineral grains. Meanwhile, it can also be found from Figure 7 that, under the same temperature, the thermal damage degree (either thermal cracking or thermal decomposition) under A condition is significantly more serious than that under $\mathrm{V}$ condition.

The ultimate failure modes of limestone specimens after heat treatment under uniaxial compression are shown in Figure 8, which can be divided into four categories, that is, tension failure, tension-shear failure, shear failure, and end failure, respectively.

(i) Tension Failure. One or more tensile fracture planes initiate on the specimen, approximatively parallel to the direction of axial stress. Obvious brittle features are presented on the limestone surface. This failure mode mainly occurs at $T=200^{\circ} \mathrm{C}$ under both $\mathrm{V}$ and A conditions and at $T=300^{\circ} \mathrm{C}$ under $\mathrm{V}$ condition.

(ii) Tension-Shear Failure. The tension failure and shear failure occur simultaneously. This failure mode mainly occurs at $T=300^{\circ} \mathrm{C}$ under A condition and at $T=450^{\circ} \mathrm{C}$ under both $\mathrm{V}$ and $\mathrm{A}$ conditions.

(iii) Shear Failure. One or more shear planes present on the specimen with an angle to the direction of axial stress. This failure mode mainly occurs at $T=600$ and $750^{\circ} \mathrm{C}$ under both $\mathrm{V}$ and $\mathrm{A}$ conditions.

(iv) End Failure. Crushing failure occurs on one end of the specimen, while other areas are relatively intact. This failure mode mainly occurs at $T=900^{\circ} \mathrm{C}$ under both $\mathrm{V}$ and A conditions.

3.3. Crack Initiation Feature. In order to investigate the fracture failure process of limestone specimens after heat treatment, the variation curves of $\mathrm{AE}$ counts and accumulative $\mathrm{AE}$ counts during the whole loading process are drawn, as shown in Figure 9. In the initial loading stage, the occurrence of $\mathrm{AE}$ counts is relatively rare and occasional. In this stage, the axial stress curve shows a concave shape. After a critical point, significant and regular AE information can be collected and the accumulative AE counts start to increase drastically. The critical point that is defined as the inflection point in the accumulative AE counts curve can be considered as the crack initiation point. The corresponding axial stress can be considered as the crack initiation stress in general [40, 41].

The variation in crack initiation stress of limestone specimens after heat treatment under uniaxial compression is shown in Figure 10(a). With the elevating temperature, the crack initiation stress and crack initiation stress level demonstrate approximate linear decrease. According to the fitting results, the linear fitting degrees between crack initiation stress and temperature under $\mathrm{V}$ and $\mathrm{A}$ conditions are very high, and the coefficients of determination $\left(R^{2}\right)$ are 0.96 and 0.99. Crack initiation stress levels under $\mathrm{V}$ and $\mathrm{A}$ conditions also have linear relationship with temperature, and $R^{2}$ are 0.98 and 0.94 , respectively. As temperature rises from 200 to $900^{\circ} \mathrm{C}$, crack initiation stress decreases from 50.22 to $11.76 \mathrm{MPa}$ under $\mathrm{V}$ condition and from 40.53 to 9.71 $\mathrm{MPa}$ under A condition, with the reduction extents of $76.58 \%$ and $76.04 \%$, respectively. In addition, the crack initiation stress is also closely related to the heating condition. On the whole, the crack initiation stress under $\mathrm{V}$ condition is always higher than that under A condition in the temperature range of 200 to $900^{\circ} \mathrm{C}$.

In addition, it is generally believed that the crack initiation stress is determined to some extent by the peak strength of rock [42-44]. On the whole, the larger the peak strength is, the larger the crack initiation stress is. In order to clearly describe the initiation feature of limestone, the crack initiation stress level $\sigma_{\mathrm{ci}} / \mathrm{UCS}$ is proposed, as shown in Figure $10(\mathrm{~b})$, in which $\sigma_{\mathrm{ci}}$ and UCS indicate the crack initiation stress and peak strength, respectively. The crack initiation stress level decreases gradually with the increasing 

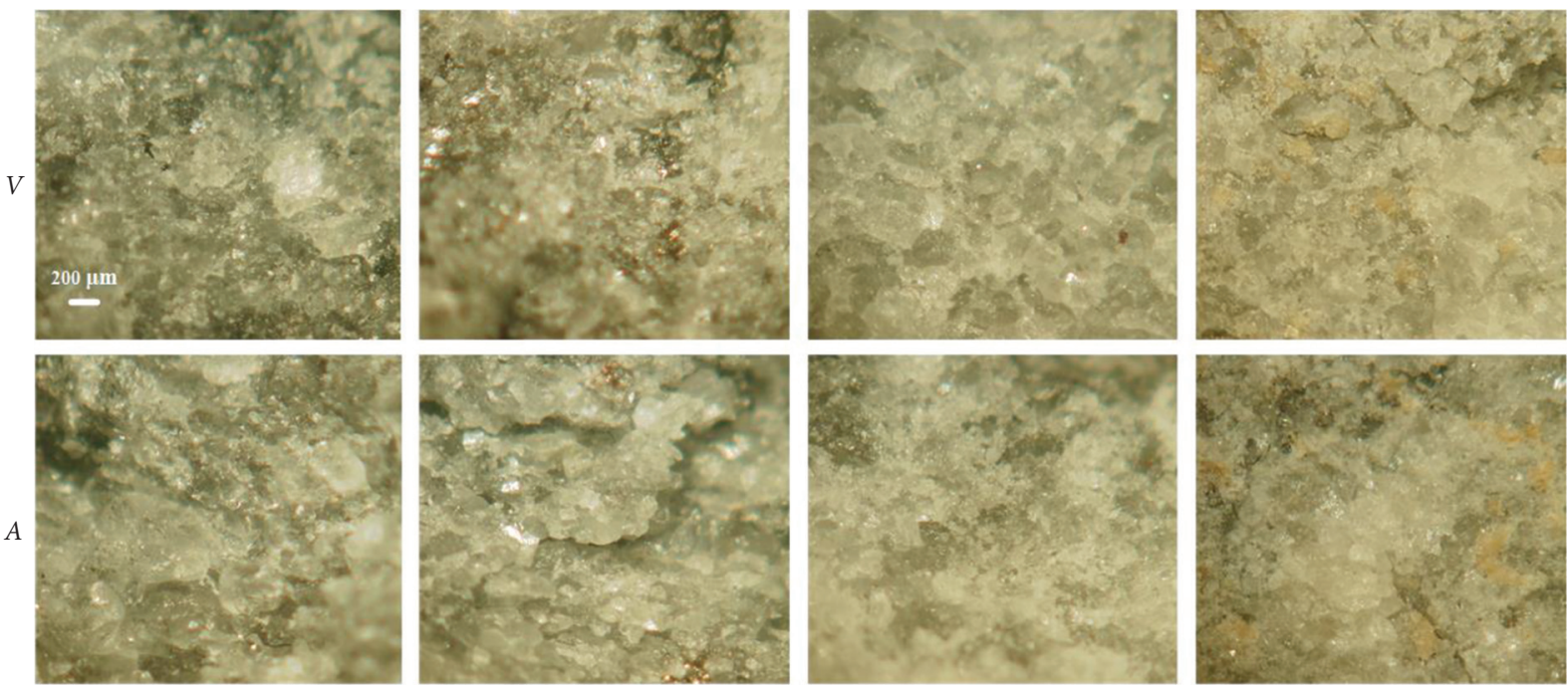

$450^{\circ} \mathrm{C}$

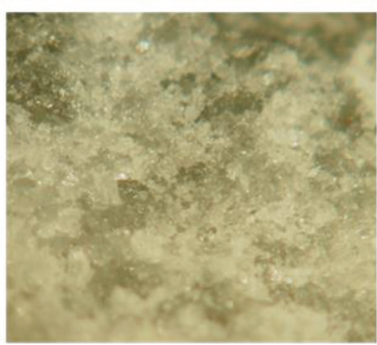

$600^{\circ} \mathrm{C}$

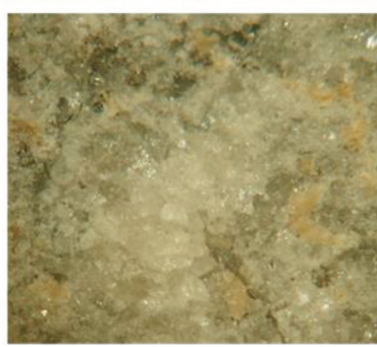

$900^{\circ} \mathrm{C}$

Figure 7: Optical microscopy results of limestone after heat treatment.
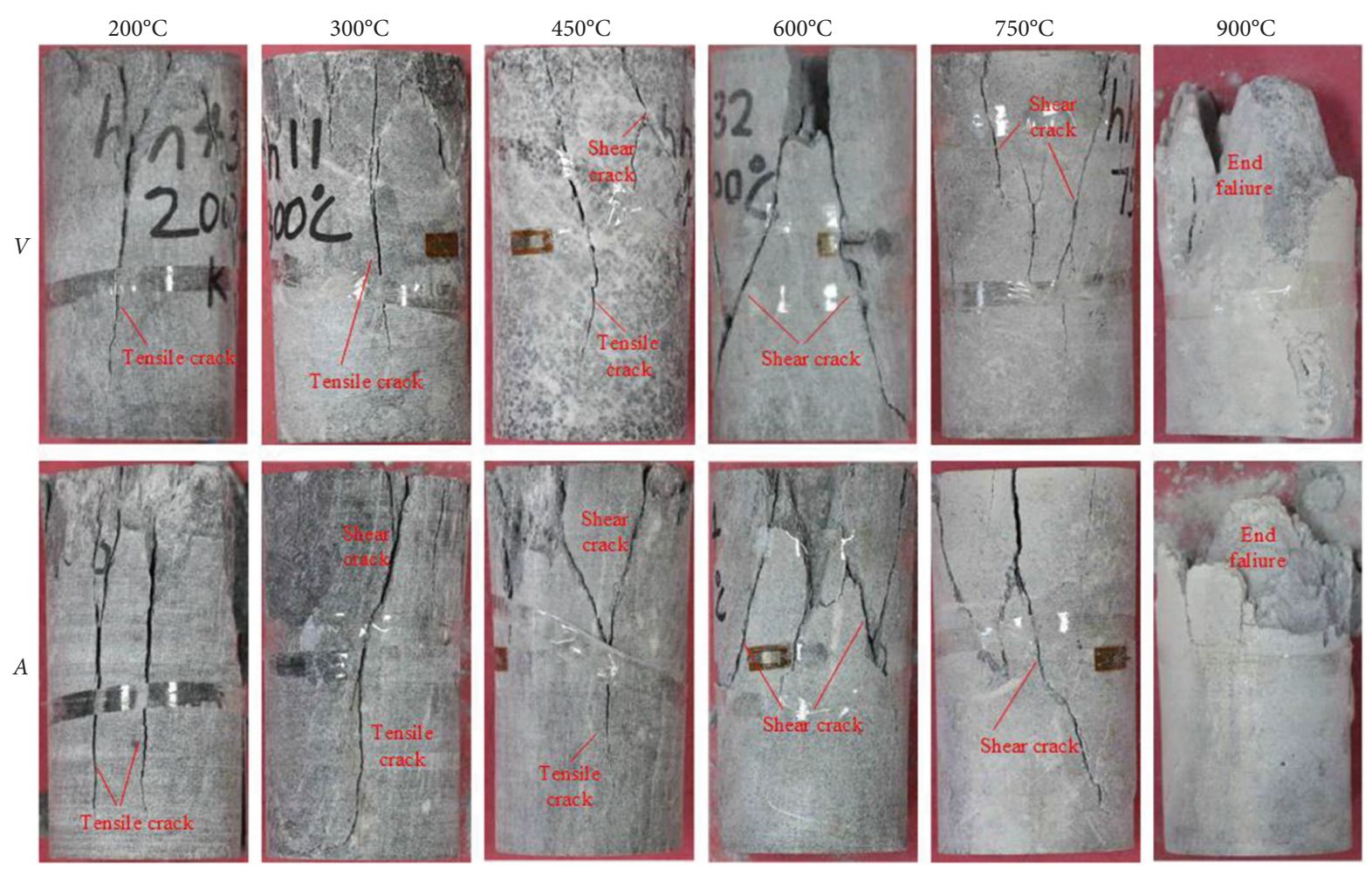

FIGURE 8: Ultimate failure modes of limestone specimens under uniaxial compression.

temperature in general under both $\mathrm{V}$ and $\mathrm{A}$ conditions, which illustrates that the elevating heating temperature accelerates the initial crack development in the loading process. Meanwhile, it can also be seen from Figure 10(b) that the heating condition is an important factor affecting the characteristics of limestone crack initiation. At the same temperature level, the crack initiation stress level under A condition is obviously smaller than that under $\mathrm{V}$ condition, which is similar to the laws shown in ultrasonic velocity and peak strength.
3.4. Pore Distribution. As a typical porous material, a large number of microscopic pores exist in the rocks. Temperature influences the physical and mechanical parameters of rocks, which would also change the pore feature as well [45-48]. NMR tests were conducted on the limestone specimens after heat treatment under different heating conditions in this study to investigate the variations in pore distribution. The variation in porosity of limestone obtained from NMR with different temperatures is shown in Figure 11, in which some results of previous literatures are also listed in $[19,35,49]$. With the 

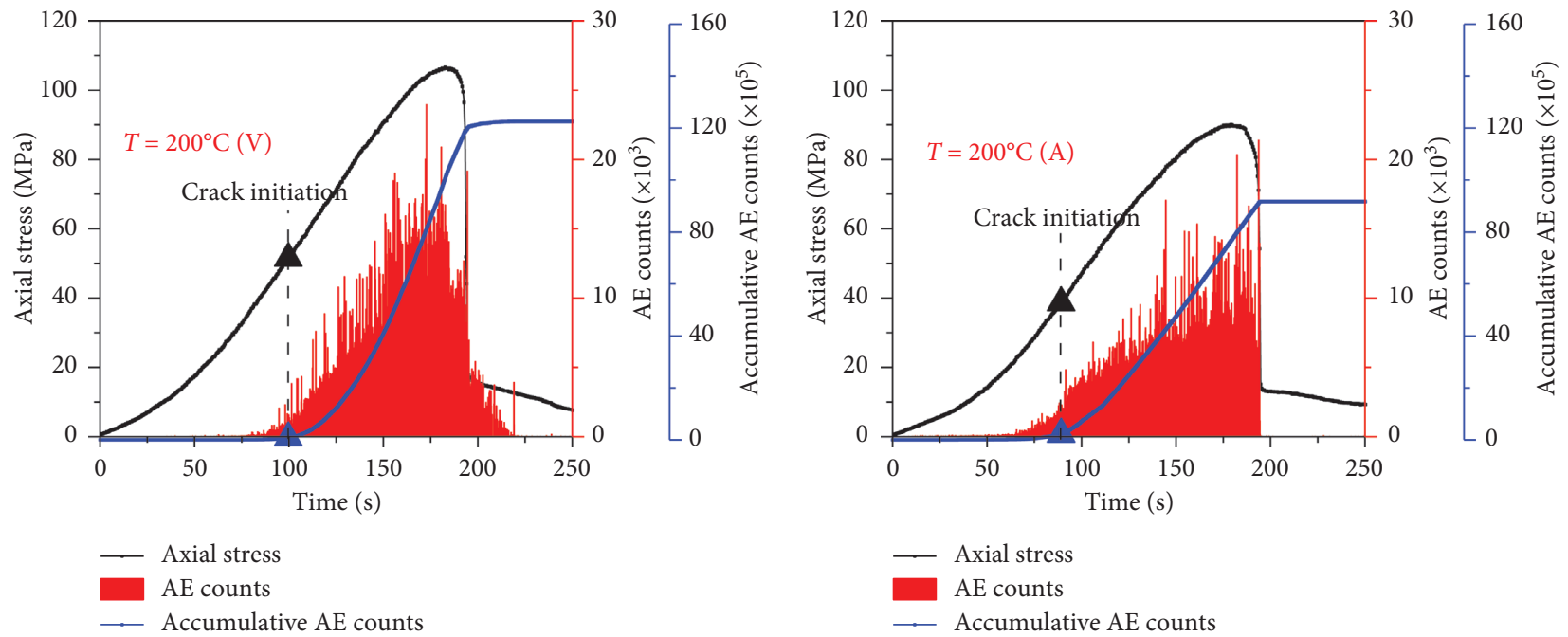

(a)
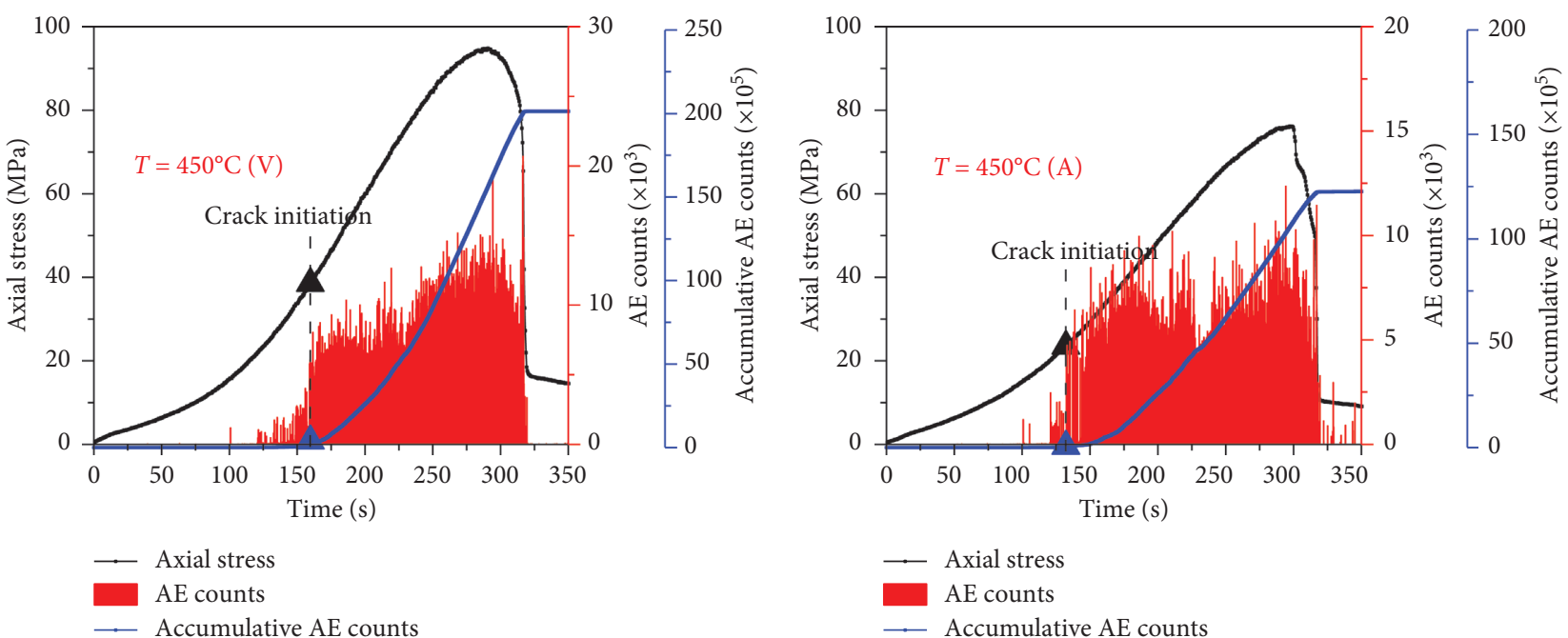

(c)

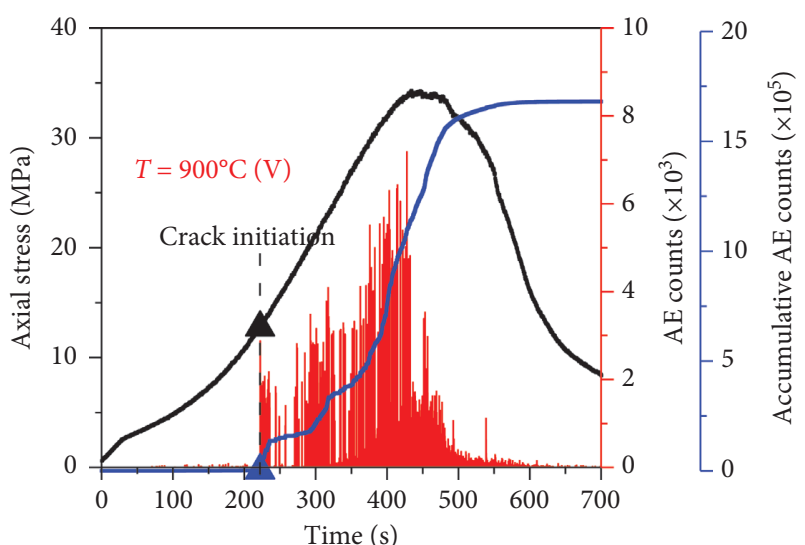

(d)

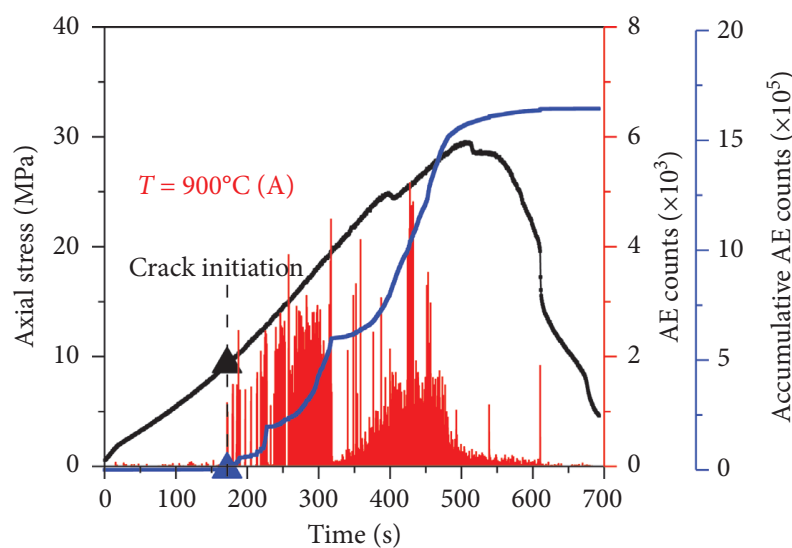

- Axial stress

AE counts

- Accumulative AE counts

$\longrightarrow$ Axial stress

AE counts

- Accumulative AE counts

(e)

(f)

FIgURE 9: AE curves of limestone specimens under uniaxial compression. 


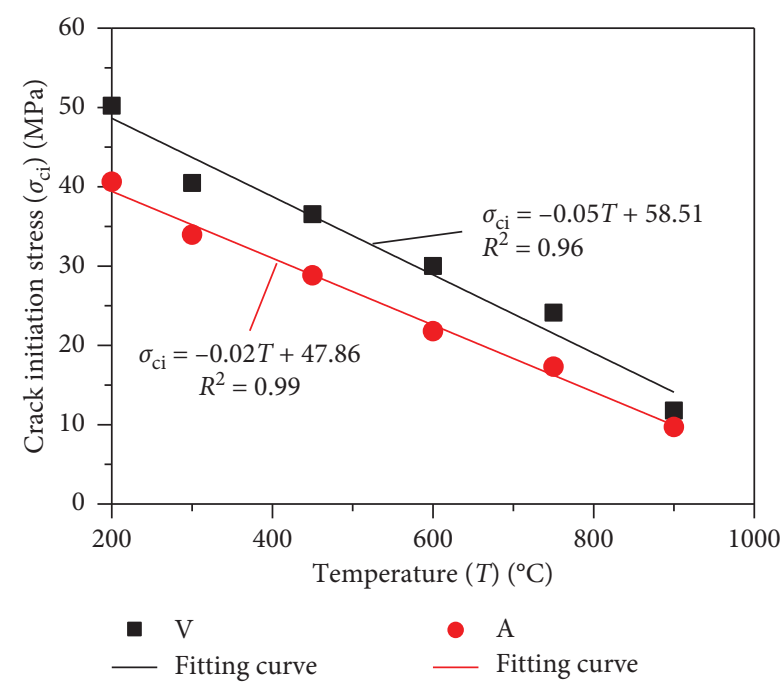

(a)

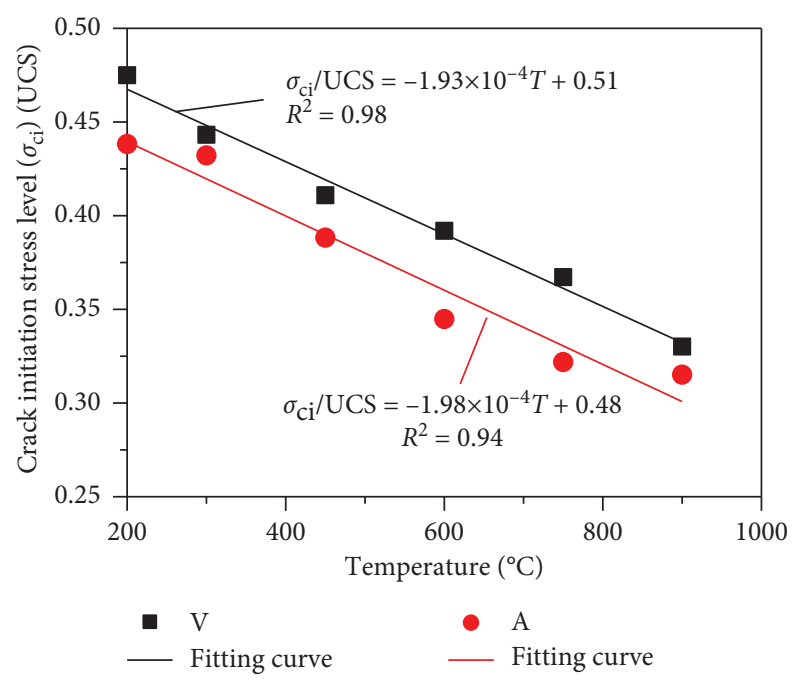

(b)

FIGURE 10: Variations in (a) crack initiation stress and (b) crack initiation stress level with different temperatures.

increase of temperature, the porosity of limestone gradually increases, presenting a feature of exponential function in general. According to the polynomial fitting results, the detailed fitting equation between porosity and temperature is $\varphi=0.28+1.65 \times 10-3 T+3.37 \times 10^{-6} T^{2}$ with $R^{2}=0.87$. In this study, as the temperature rises from 25 to $900^{\circ} \mathrm{C}$, porosity increases from $0.23 \%$ (room temperature) to $4.15 \%$ (V condition) and $4.87 \%$ (A condition), respectively. Moreover, it is obvious that heating condition has a significant effect on the porosity of limestone. Taking $T=450^{\circ} \mathrm{C}$ as the example, the porosity is $1.15 \%$ for $\mathrm{V}$ condition and $2.50 \%$ for A condition with the increase extent of $117.39 \%$. With the circulation of the air in the heating furnace, high-temperature treatment causes more pores.

In NMR tests, the transverse relaxation time $\left(T_{2}\right)$ can be calculated and used to characterize the pore distributions of rocks. $T_{2}$ is positively correlated with pore volume and pore radius and negatively correlated with pore area, and the signal amplitude of $T_{2}$ can reflect the number of pores with different radii $[23,24]$. The peak value and area of $T_{2}$ curve reflect the number of pores, and the continuity of $T_{2}$ curve reflects the connectivity characteristics of pores [50]. The $T_{2}$ curves obtained by NMR tests are illustrated in Figure 12 . As $T=25^{\circ} \mathrm{C}$, the $T_{2}$ curve of limestone presents a double-peak feature, with a larger signal amplitude for the second peak than that for the first one. As $T=450^{\circ} \mathrm{C}$, the $T_{2}$ curves show a same double-peak feature as that of $T=25^{\circ} \mathrm{C}$, but the signal amplitudes of peak point are apparently different. The peak signal amplitude of $T=450^{\circ} \mathrm{C}$ is 536.94 for $\mathrm{V}$ condition and 1510.60 for A condition, while it was only 108.02 for $T=25^{\circ} \mathrm{C}$. As $T=900^{\circ} \mathrm{C}$, the $T_{2}$ curve for $\mathrm{V}$ condition still keeps the double-peak feature in general, with a larger peak signal amplitude of 1365.62 compared with that of $T=450^{\circ} \mathrm{C}$, while, for A condition, the shape of $T_{2}$ curve changes to the single-peak feature, with the peak signal amplitude of 2230.12.

In this study, the pore radius can be divided into four regions: $0 \sim 0.1 \mu \mathrm{m}$ (tiny pore), $0.1 \sim 1.0 \mu \mathrm{m}$ (small pore),
$1.0 \sim 10.0 \mu \mathrm{m}$ (medium pore), and $>10.0 \mu \mathrm{m}$ (large pore). Figure 12 also shows the pore distribution of limestone after heat treatment under different conditions. As $T=25^{\circ} \mathrm{C}, \mathrm{Pe}$ $(0 \sim 0.1 \mu \mathrm{m}), \mathrm{Pe}(0.1 \sim 1.0 \mu \mathrm{m})$, Pe $(1.0 \sim 10.0 \mu \mathrm{m})$, and $\mathrm{Pe}$ ( > $10.0 \mu \mathrm{m}$ ) are $17.96 \%, 33.51 \%, 43.48 \%$, and $5.05 \%$, respectively. With the increase of temperature from 25 to $450^{\circ} \mathrm{C}, \mathrm{Pe}$ $(0 \sim 0.1 \mu \mathrm{m}), \operatorname{Pe}(0.1 \sim 1.0 \mu \mathrm{m})$, and $\mathrm{Pe}(1.0 \sim 10.0 \mu \mathrm{m})$ show a decrease, while $\operatorname{Pe}(>10.0 \mu \mathrm{m})$ increases from $5.05 \%$ to $42.39 \%$ for $\mathrm{V}$ condition and to $69.00 \%$ for A condition. However, from 450 to $900^{\circ} \mathrm{C}, \mathrm{Pe}(1.0 \sim 10.0 \mu \mathrm{m})$ increases from $41.02 \%$ to $50.87 \%$ for $\mathrm{V}$ condition and from $21.91 \%$ to $67.86 \%$ for $\mathrm{A}$ condition, while $\mathrm{Pe}(>10.0 \mu \mathrm{m})$ decreases from $42.39 \%$ to $15.18 \%$ for $\mathrm{V}$ condition and from $69.00 \%$ to $27.94 \%$ for $\mathrm{A}$ condition.

From Figures 11 and 12, the evolution process of pore structure of limestone with the increase of temperature (from room temperature to $900^{\circ} \mathrm{C}$ ) can be deduced, as shown in Figure 13. With the increase of temperature, firstly, the mineral grain of limestone shows nonuniform thermal expansion and the losses of bound water and interlayer water, which leads to the initiation of new pores and the growth of previous pores. Meanwhile, pore distribution transforms from small and medium pores dominating to large pore dominating. With the further increase of temperature, the mineral grain presents strongly thermal decomposition and cracking, resulting in the redistribution of microscopic structure. Some large pores are filled by a part of mineral grains after thermal cracking and decomposition. The total volume of pores continues to increase in general, resulting in the continued increase in porosity. However, due to the fact that some large pores are cut off, the percentage of large pore decreases unexpectedly. The pore distribution changes to medium pores dominating ultimately at the temperature of $900^{\circ} \mathrm{C}$.

To further confirm the conjecture about pore evolution, microstructure images were taken with a TESCAN VEGA 4 scanning electron microscope. The microstructure images of limestone specimens with different temperature and heating 


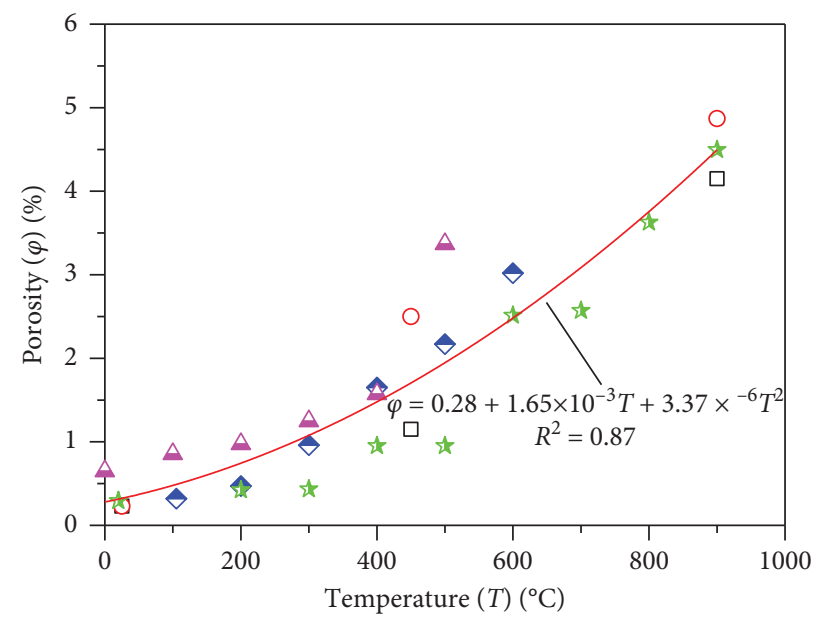
口 This study $(\mathrm{V})$
$\Delta \quad$ Yavuz et al. (2010)
○ This study (A)
* Zhang et al. (2016)
$\diamond$ Sengun (2014)
— Fitting curve

FIGURE 11: Effect of temperature on the porosity of limestone.

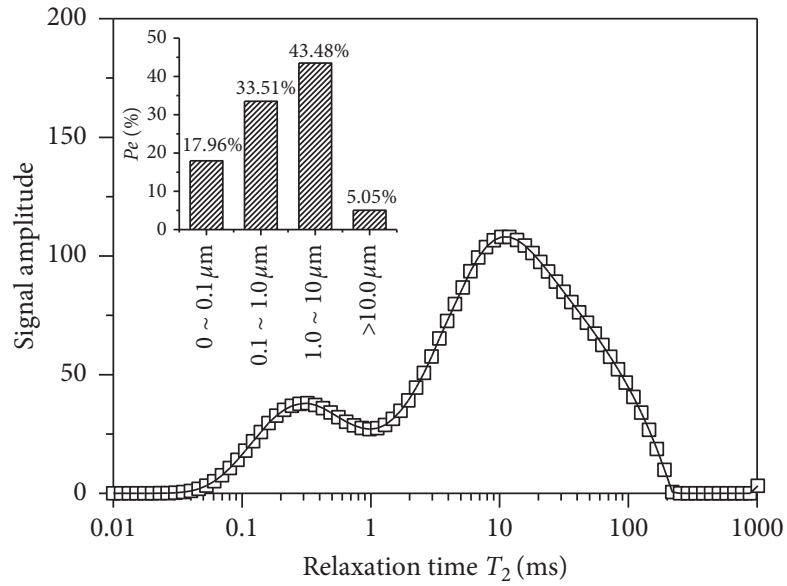

(a)

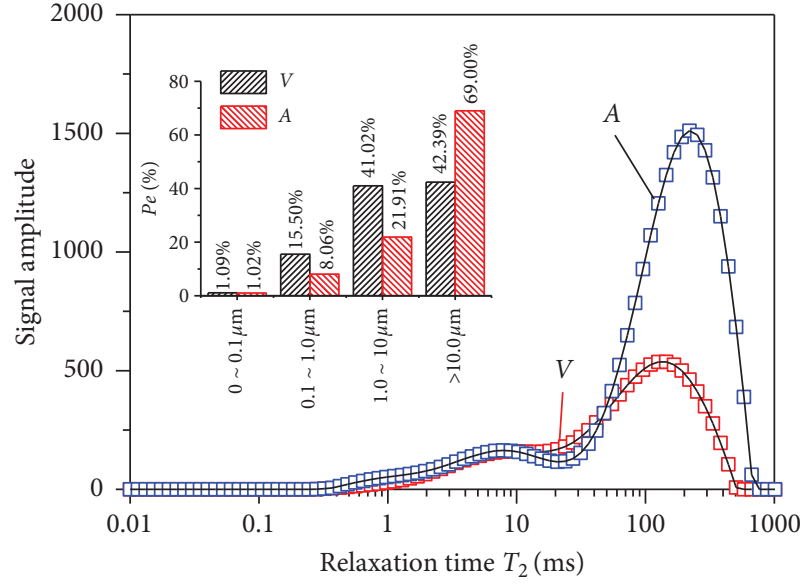

(b)

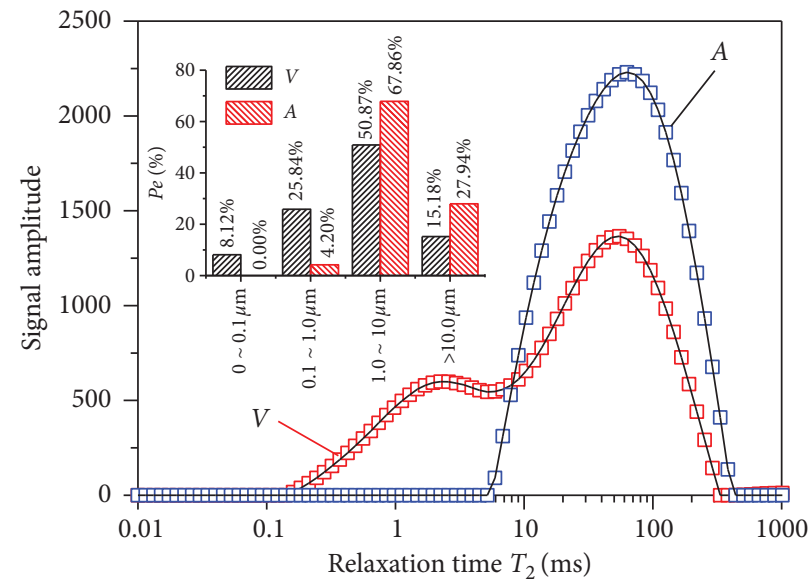

(c)

Figure 12: $T_{2}$ curve and pore distribution of limestone after heat treatment at the temperature of (a) $25^{\circ} \mathrm{C}$, (b) $450^{\circ} \mathrm{C}$, and (c) $900^{\circ} \mathrm{C}$, respectively. 


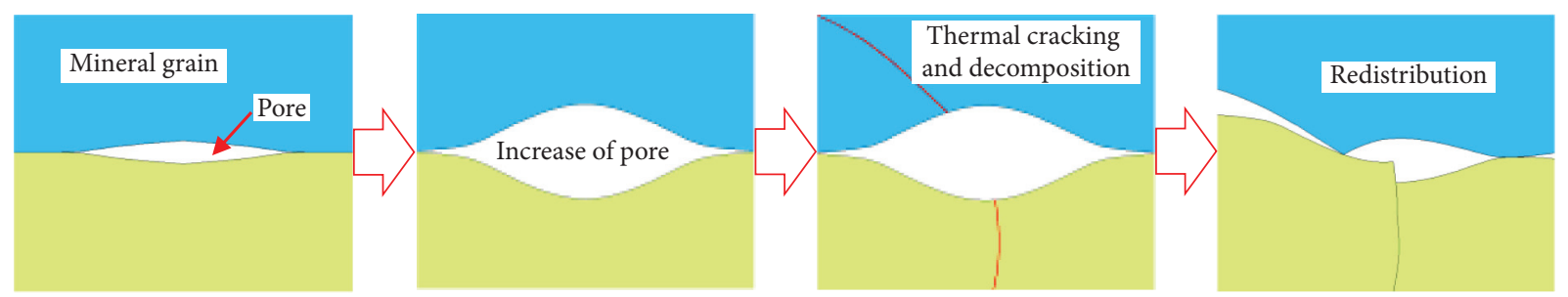

FIGURE 13: Evolution process of microscopic structure of limestone with the increasing temperature.

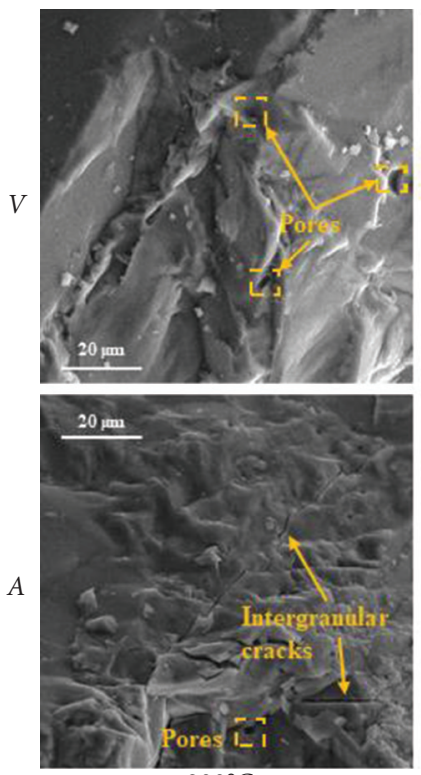

$200^{\circ} \mathrm{C}$
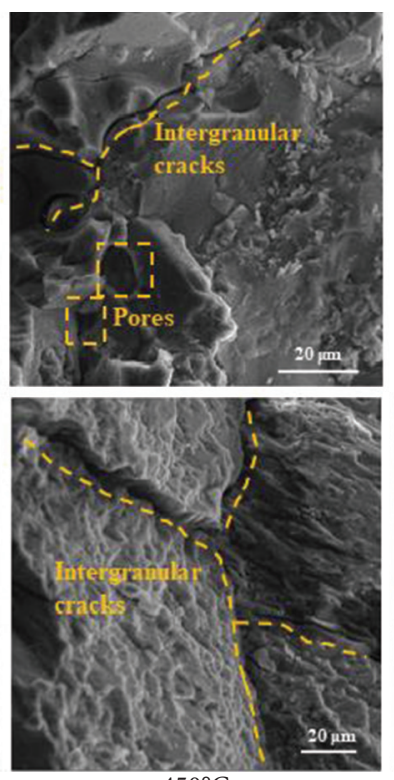

$450^{\circ} \mathrm{C}$
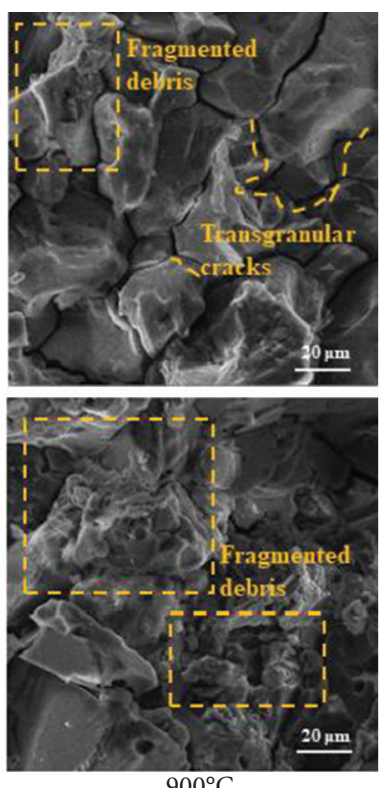

FIGURE 14: SEM images of thermally treated limestone specimens with different temperature and heating conditions.

conditions are displayed in Figure 14. From the natural state SEM image in Figure 1, it can be found that the mineral particles are cemented tightly, and no obvious cracks are observed. For limestone specimens after heating treatment of $200^{\circ} \mathrm{C}$, small pores are distributed on the specimen surface. Under A condition, the cementation between particles is further weakened and tiny intergranular cracks are generated. When the limestone specimens are heated to $450^{\circ} \mathrm{C}$, the amount and diameter of pores get development. Besides, some intergranular cracks start to connect with each other and microcracks with large length and aperture are formed around crystals. When the temperature reaches $900^{\circ} \mathrm{C}$, lots of transgranular cracks appear around the crystal and connected cracknet is generated and the fragmented debris around the cracknet is also removed in this process. Owing to the melt and reconsolidation of mineral grains, some large pores are filled. The interconnected microcracks can dramatically increase the porosity and deteriorate the mechanical properties of rocks.

\section{Conclusions}

In this study, limestone specimens were heated to different set of temperatures under approximate vacuum and air circulation condition, respectively. Then, ultrasonic velocity tests, uniaxial compression tests and NMR tests were conducted to study the effects of heating condition on the physical, mechanical, and pore distribution of thermally treated limestone. Combined with the AE method and NMR results, the crack initiation behaviors and pore features were quantitatively evaluated.

With the increasing temperature, physical and mechanical parameters including density, ultrasonic velocity, peak strength, elasticity modulus, and secant modulus all show different degrees of deterioration. The initial crack development of limestone specimens during loading process is also aggravated on account of the high temperature. Within the temperature range of $450 \sim 750^{\circ} \mathrm{C}$, the mechanical properties under $\mathrm{V}$ condition are obviously larger than those under $\mathrm{A}$ condition, which may result from the thermal damage of limestone aggravated by air circulation. From room temperature to $900^{\circ} \mathrm{C}$, pore distribution changes from small and medium pores dominating to large pore dominating and then to medium pore dominating due to the redistribution of pore structure caused by the thermal cracking and the reconsolidation of mineral grains.

Note that the experiment is a mechanical experiment on the limestone specimens which experienced high temperature and naturally cooling treatment, not under the condition of real-time high temperature. High temperature would melt the mineral compositions inside the rocks, and the minerals would 
be reconsolidated after the rocks are cooled to room temperature. The new cementation of minerals may have a vital impact on the thermal effect of rocks and the stability of rock engineering, which needs to be explored in the future work.

\section{Data Availability}

The data used to support the findings of this study are available from the corresponding author upon request.

\section{Conflicts of Interest}

The authors declare that they have no conflicts of interest.

\section{Acknowledgments}

This study was financed by the National Natural Science Foundation of China (nos. 42077240 and 51904290).

\section{References}

[1] T. H. Fairs, P. L. Younger, and G. Parkin, "Parsimonious numerical modelling of deep geothermal reservoirs," Proceedings of the Institution of Civil Engineers-Energy, vol. 168, no. 4, pp. 218-228, 2015.

[2] B. Edwards, T. Kraft, C. Cauzzi, P. Kastli, and S. Wiemer, "Seismic monitoring and analysis of deep geothermal projects in st gallen and basel, Switzerland," Geophysical Journal International, vol. 201, no. 2, pp. 1022-1039, 2015.

[3] Q. Z. Guo, H. J. Su, J. W. Liu, Q. Yin, H. W. Jing, and L. Y. Yu, "An experimental study on the fracture behaviors of marble specimens subjected to high temperature treatment," Engineering Fracture Mechanics, vol. 225, Article ID 106862, 2020.

[4] J. Yu, S.-j. Chen, X. Chen, Y.-z. Zhang, and Y.-y. Cai, "Experimental investigation on mechanical properties and permeability evolution of red sandstone after heat treatments," Journal of Zhejiang University-Science, vol. 16, no. 9, pp. 749-759, 2015.

[5] S. T. Miao, P. Z. Pan, P. Y. Yu, S. K. Zhao, and C. Y. Shao, "Fracture analysis of Beishan granite after high-temperature treatment using digital image correlation," Engineering Fracture Mechanics, vol. 225, Article ID 106847, 2020.

[6] S.-Q. Yang, Y.-H. Huang, W.-L. Tian, P.-F. Yin, and H.-W. Jing, "Effect of high temperature on deformation failure behavior of granite specimen containing a single fissure under uniaxial compression," Rock Mechanics and Rock Engineering, vol. 52, no. 7, pp. 2087-2107, 2019.

[7] F. Gong, S. Luo, G. Lin, and X. Li, "Evaluation of shear strength parameters of rocks by preset angle shear, direct shear and triaxial compression tests," Rock Mechanics and Rock Engineering, vol. 53, no. 5, pp. 2505-2519, 2020.

[8] Y. Wang, X. Shang, and K. Peng, "Relocating mining microseismic earthquakes in a $3-\mathrm{D}$ velocity model using a windowed cross-correlation technique," IEEE Access, vol. 8, pp. 37866-37878, 2020.

[9] B. Mahanta, T. N. Singh, and P. G. Ranjith, "Influence of thermal treatment on mode i fracture toughness of certain Indian rocks," Engineering Geology, vol. 210, pp. 103-114, 2016.

[10] F. Gong, J. Yan, S. Luo, and X. Li, "Investigation on the linear energy storage and dissipation laws of rock materials under uniaxial compression," Rock Mechanics and Rock Engineering, vol. 52, no. 11, pp. 4237-4255, 2019.
[11] K. Peng, J. Zhou, Q. Zou, and X. Song, "Effect of loading frequency on the deformation behaviours of sandstones subjected to cyclic loads and its underlying mechanism," International Journal of Fatigue, vol. 131, Article ID 105349, 2020.

[12] C. Yan, J. Deng, B. Yu et al., "Borehole stability in hightemperature formations," Rock Mechanics and Rock Engineering, vol. 47, no. 6, pp. 2199-2209, 2014.

[13] A. Hassanzadegan, G. Blöcher, H. Milsch, L. Urpi, and G. Zimmermann, "The effects of temperature and pressure on the porosity evolution of Flechtinger sandstone," Rock Mechanics and Rock Engineering, vol. 47, no. 2, pp. 421-434, 2014.

[14] M. Hajpal and A. Török, "Mineralogical and colour changes of quartz sandstones by heat," Environmental Geology, vol. 46, no. 3, pp. 311-322, 2004.

[15] R. D. Dwivedi, R. K. Goel, V. V. R. Prasad, and A. Sinha, "Thermo-mechanical properties of Indian and other granites," International Journal of Rock Mechanics and Mining Sciences, vol. 45, no. 3, pp. 303-315, 2008.

[16] K. Kim, J. Kemeny, and M. Nickerson, "Effect of rapid thermal cooling on mechanical rock properties," Rock Mechanics and Rock Engineering, vol. 47, no. 6, pp. 2005-2019, 2014.

[17] P. G. Ranjith, D. R. Viete, B. J. Chen, and M. S. A. Perera, "Transformation plasticity and the effect of temperature on the mechanical behaviour of Hawkesbury sandstone at atmospheric pressure," Engineering Geology, vol. 151, pp. 120127, 2012.

[18] K. Peng, H. Lv, F. Yan, Q. Zou, X. Song, and Z. Liu, "Effects of temperature on mechanical properties of granite under different fracture modes," Engineering Fracture Mechanics, vol. 226, Article ID 106838, 2020.

[19] H. Yavuz, S. Demirdag, and S. Caran, "Thermal effect on the physical properties of carbonate rocks," International Journal of Rock Mechanics and Mining Sciences, vol. 47, no. 1, pp. 94-103, 2010.

[20] K. Peng, H. Lv, Q. Zou, Z. Wen, and Y. Zhang, "Evolutionary characteristics of mode-I fracture toughness and fracture energy in granite from different burial depths under hightemperature effect," Engineering Fracture Mechanics, vol. 239, Article ID 107306, 2020.

[21] Y. Zhang, Q. Sun, H. He, L. Cao, W. Zhang, and B. Wang, "Pore characteristics and mechanical properties of sandstone under the influence of temperature," Applied Thermal Engineering, vol. 113, pp. 537-543, 2017.

[22] Q. Yin, H. Jing, R. Liu, H. Su, L. Yu, and G. Han, "Pore characteristics and nonlinear flow behaviors of granite exposed to high temperature," Bulletin of Engineering Geology and the Environment, vol. 79, no. 3, pp. 1239-1257, 2019.

[23] H. Zhang, Q. Sun, H. Jia, Z. Dong, and T. Luo, "Effects of high-temperature thermal treatment on the porosity of red sandstone: an NMR analysis," Acta Geophysica, vol. 69, no. 1, pp. 113-124, 2021.

[24] L. Weng, Z. Wu, and Q. Liu, "Evaluating damage and microcracking behavior of granite using NMR testing under different levels of unconfined compression," International Journal of Geomechanics, vol. 19, no. 1, 2019.

[25] A. K. A. El-Aal and A. A. Masoud, "Impacts of karst phenomena on engineering properties of limestone foundation bed, Ar Riyadh, Saudi Arabia," Arabian Journal of Geosciences, vol. 10, p. 347, 2017.

[26] C. Wang, Z. Lu, L. Liu, X. Chuai, and H. Lu, "Predicting points of the infrared precursor for limestone failure under uniaxial compression," International Journal of Rock Mechanics and Mining Sciences, vol. 88, no. 10, pp. 34-43, 2016. 
[27] M. Xu, E. Song, and J. Chen, "A large triaxial investigation of the stress-path-dependent behavior of compacted rockfill," Acta Geotechnica, vol. 7, no. 3, pp. 167-175, 2012.

[28] Y. Zhang, Q. Sun, L. Cao, and J. Geng, "Pore, mechanics and acoustic emission characteristics of limestone under the influence of temperature," Applied Thermal Engineering, vol. 123, pp. 1237-1244, 2017.

[29] Z. K. Crosby, P. M. Gullett, S. A. Akers, and S. S. Graham, "Characterization of the mechanical behavior of salem limestone containing thermally-induced microcracks," International Journal of Rock Mechanics and Mining Sciences, vol. 101, pp. 54-62, 2018.

[30] W. G. P. Kumari, P. G. Ranjith, M. S. A. Perera, B. K. Chen, and I. M. Abdulagatov, "Temperature-dependent mechanical behaviour of Australian strathbogie granite with different cooling treatments," Engineering Geology, vol. 229, pp. 31-44, 2017.

[31] E. Rossi, M. A. Kant, C. Madonna, M. O. Saar, and P. Rudolf Von Rohr, "The effects of high heating rate and high temperature on the rock strength: feasibility study of a thermally assisted drilling method," Rock Mechanics and Rock Engineering, vol. 51, no. 9, pp. 2957-2964, 2018.

[32] Y. Feng, H. Su, W. Zhang, L. Yu, and Q. Yin, "Experimental study on mechanical behaviors and fracture features of coarse marble specimens after thermal shock," International Journal of Geomechanics, vol. 21, no. 6, 2021.

[33] L. Y. Yu, H. J. Su, R. C. Liu, H. W. Jing, G. L. Li, and M. Li, "Effect of thermal treatment on the dynamic behaviors at a fixed loading rate of limestone in quasi-vacuum and air-filled environments," Latin American Journal of Solids and Structures, vol. 15, no. 3, 2018.

[34] H. J. Su, H. W. Jing, Q. Yin, and L. Y. Yu, Effect of thermal environment on the mechanical behaviors of building marble," Advances in Civil Engineering, vol. 2018, Article ID 1326503, , 2018.

[35] W. Zhang, Q. Sun, S. Hao, and B. Wang, "Experimental study on the thermal damage characteristics of limestone and underlying mechanism," Rock Mechanics and Rock Engineering, vol. 49, no. 8, pp. 2999-3008, 2016.

[36] Z.-n. Zhu, H. Tian, G.-s. Jiang, and W. Cheng, "Effects of high temperature on the mechanical properties of chinese marble," Rock Mechanics and Rock Engineering, vol. 51, no. 6, pp. 1937-1942, 2018.

[37] Z. C. Tang, Q. Z. Zhang, and J. Peng, "Effect of thermal treatment on the basic friction angle of rock joint," Rock Mechanics and Rock Engineering, vol. 53, pp. 1-18, 2019.

[38] W. Zhang, Q. Sun, and Y. Zhang, "Effects of pre-existing cracks and temperature on failure mode of granite from eastern china," Journal of Structural Geology, vol. 126, pp. 330-337, 2019.

[39] W.-L. Tian, S.-Q. Yang, and Y.-H. Huang, "Macro and micro mechanics behavior of granite after heat treatment by cluster model in particle flow code," Acta Mechanica Sinica, vol. 34, no. 1, pp. 175-186, 2018.

[40] S. Miao, P.-Z. Pan, Z. Wu, S. Li, and S. Zhao, "Fracture analysis of sandstone with a single filled flaw under uniaxial compression," Engineering Fracture Mechanics, vol. 204, pp. 319-343, 2018.

[41] S.-Q. Yang, X.-R. Liu, and H.-W. Jing, "Experimental investigation on fracture coalescence behavior of red sandstone containing two unparallel fissures under uniaxial compression," International Journal of Rock Mechanics and Mining Sciences, vol. 63, pp. 82-92, 2013.
[42] H. D. Liu, L. D. Li, S. L. Zhao, and S. H. Hu, "Complete stressstrain constitutive model considering crack model of brittle rock," Environmental Earth Sciences, vol. 78, no. 21, p. 629, 2019.

[43] Y. Wang, C. H. Li, Y. Z. Hu, and X. L. Zhou, "A new method to evaluate the brittleness for brittle rock using crack initiation stress level from uniaxial stress-strain curves," Environmental Earth Sciences, vol. 76, no. 23, p. 799, 2017.

[44] C. J. Jia, W. Y. Xu, H. L. Wang, W. Wang, J. Yu, and Z. N. Lin, "Laboratory investigations of inert gas flow behaviors in compact sandstone," Environmental Earth Sciences, vol. 77, no. 6, p. 245, 2018.

[45] Q.-B. Meng, C.-K. Wang, J.-F. Liu, M.-W. Zhang, M.-M. Lu, and $\mathrm{Y}$. Wu, "Physical and micro-structural characteristics of limestone after high temperature exposure," Bulletin of Engineering Geology and the Environment, vol. 79, no. 3, pp. 1259-1274, 2020.

[46] J. J. Hu, X. H. Pan, and W. Q. Zhang, "Thermal effect on wave velocity of sandstone after high-temperature treatment: a review," Arabian Journal of Geosciences, vol. 12, no. 22, p. 689, 2019.

[47] P. Xu and S.-Q. Yang, "Influence of stress and high-temperature treatment on the permeability evolution behavior of sandstone," Acta Mechanica Sinica, vol. 35, no. 2, pp. 419-432, 2019.

[48] A. Ozguven and Y. Ozcelik, "Effects of high temperature on physico-mechanical properties of Turkish natural building stones," Engineering Geology, vol. 183, pp. 127-136, 2014.

[49] N. Sengun, "Influence of thermal damage on the physical and mechanical properties of carbonate rocks," Arabian Journal of Geosciences, vol. 7, no. 12, pp. 5543-5551, 2014.

[50] G. P. Frosch, J. E. Tillich, R. Haselmeier, M. Holz, and E. Althaus, "Probing the pore space of geothermal reservoir sandstones by nuclear magnetic resonance," Geothermics, vol. 29, no. 6, pp. 671-687, 2000. 